\title{
Evaluation of Ultra Violet Emissions Radiated From Compact Fluorescent Lamps of Iranian Current Brands
}

\author{
Shahram Safari ${ }^{1}$, Meghdad Kazemi ${ }^{1}$, Hossein Ali Yousefi ${ }^{1}$, Habibollah Dehghan ${ }^{1, *}$, Behzad \\ Mahaki $^{2}$ \\ ${ }^{1}$ Department of Occupational Health Engineering, School of Health, Isfahan University of Medical Sciences, Isfahan, IR Iran \\ ${ }^{2}$ Department of Statistics and Epidemiology, School of Health, Isfahan University of Medical Sciences, Isfahan, IR Iran \\ *Corresponding author: Habibollah Dehghan, Department of Occupational Health Engineering, School of Health, Isfahan University of Medical Sciences, Isfahan, IR Iran. Tel: +98- \\ 3117922733, Fax: +98-3116682509, E-mail: ha_dehghan@hlth.mui.ac.ir.
}

Received: May 25, 2013; Revised: July 11, 2013; Accepted: July 15, 2013

\begin{abstract}
Background:Compact fluorescent lamp(CFL) is a developed fluorescent lamp type designed to saving energy. CFLs can cause an increased health risk to humans due to the ultraviolet radiation.

Objectives: The current study aimed to assess the ultraviolet radiation emitted from compact fluorescent lamps in highly used Iranian brands.

Materials and Methods: This experimental study was conducted on 16 CFLs that were manufactured by four Iranian manufacturers including: Pars Khazar, Parmis, Etehad and Nama Noor. The CFLs were marked as 11,18, 40 and 60 Watt. Measurement was done in 10, 25, 50, 100,150 and $200 \mathrm{~cm}$ in three angles including $0^{\circ}, 45^{\circ}$ and $90^{\circ}$ using a calibrated UV-meter. All the CFLs are aged for one hundred hours in the laboratory. The information was analyzed using SPSS-20 and ANOVA test.

Results: Measurement of UV showed that UVC emission was not observed at the distance of $10 \mathrm{~cm}$ in all of CFLs lamps. UVB irradiance in most of lamps in 10 and $25 \mathrm{~cm}$ was more than occupational exposure limits (OEL), but in $50 \mathrm{~cm}$ was less than OEL. One way ANOVA indicated that differences between UVB irradiance of four brands of lamps were not significant statistically $(\mathrm{P}>0.05)$. UVA irradiance of all CFLs lamps in $25 \mathrm{~cm}$ was less than OEL. One way ANOVA indicated that differences between UVA statistically were not significant $(\mathrm{P}>0.05)$. Conclusions: Based on the results of this study, authors recommended that CFLs lamps, due to UV radiation, especially in UVB span, be used at distances greater than $25 \mathrm{~cm}$.Compact Fluorescent Lamp (CFL) is a developed fluorescent lamp type designed for saving energy. CFLs can cause the health risk increase in humans due to the ultraviolet radiation.
\end{abstract}

Keywords: Ultraviolet Rays; UV Exposure; UVA; UVB; UVC; Fluorescent Lamp

\section{Introduction}

The compact fluorescent lamps (CFLs) are used widespread in the offices, industrial buildings, hospitals, universities, and similar premises (1). The replacement of incandescent light converting $10 \%$ of the electricity consumed into light has benefits to the community and environment. CFLs consume 4-5 times less energy for the same light output (2). Engineering data suggested 20 Watt CFL that can be replaced by 100 Watt in candescent bulbs (3). Using less energy reduces the amount of green house gas emissions and has the potential to lower the cost of electricity which benefits both individual and industry whilst helping the environment (4). Another great advantage to CFLs compared to traditional incandescent bulbs includes: 1) CFLs which have a life span of between 6,000 and 15,000 hours and last six to twenty times longer than incandescent bulbs, 2) CFLs produce about 75 percent less heat, so they're safer to operate and can cut energy costs associated with home cooling (5). CFLs relative to incandescent lamp have some disadvantages such as greater use of materials, use of toxic mercury in the tube gases, their poor power factor and high harmonic current demand plus the potential, electromagnetic interference effectdue to nature of their electronic ballast, there are also lingering concerns in the community about dimness and colorand ultra violet (UV) irradiance (6). In CFLs, UV light is produced by electric discharge in mercury vapor, which excites the phosphor material coated inside the glass envelop of the lamp and finally produces visible light. CFLs radiate a different light spectrum from those incandescent lamps. Ideally, conversion of UV to visible light should be $100 \%$; however, due to the defect in phosphor coating, output light contains trace amount of UV radiation (7-10). The feature that characterizes the properties of any particular region of the spectrum is the wave length of the radiation. UV Radiation spans are the wave length region from 400 to $100 \mathrm{~nm}$ (11), that is further subdivided into three regions:

Implication for health policy/practice/research/medical education:

In order to determine the distance of CFLs bulbs, this paper, has been developed and the results for public education to reduce exposure to UV can be useful.

Copyright (C) 2013, Health promotion research center. This is an open-access article distributed under the terms of the Creative Commons Attribution License, which permits unrestricted use, distribution, and reproduction in any medium, provided the original work is properly cited. 
UVA (315 nm-400 nm), UVB (280 nm-315 nm), and UVC (100 $\mathrm{nm}-280 \mathrm{~nm}$ ) (12). Because of their mercury content, CFLs, emitted significant quantities of UVA, epically at $365 \mathrm{~nm}$. Many of the CFLs had sizeable outputs at $313 \mathrm{~nm}$ (UVB) and in some cases, at $254 \mathrm{~nm}$ (UVC) (3). Information provided by different manufacturers shows the emissions spectra of "typical" bulbs, which are adjusted for different colors in the visible light, without any emission in the UV range (13). However, a recent study performed a general survey of the emissions from commercially available bulbs and found significant amounts of UVA and C light (14). In a study by Eadie et al.results revealed that irradiance of UV in three $11 \mathrm{~W}$ of CFLs with the same brand was different (15). In study by Klein et al. 26 CFLs in five brands including: general electric (GE), lights of America, N.vision, Philips and Sylvania the measurement of UV irradiance showed that brand of Philips was the safest. They emitted the lowest levels of UVA, UVB and UVC (16). The cost of electricity has increased in recent years and people use compact fluorescent lamps that consume 4-5 times less energy relative to incandescent lamps and because of nature of produced light in CFLs, ultra violet radiation is generated and UV irradiance is different regarding the value of different brand of CFLs, the present study aimed to evaluate UV emissions radiated from compact fluorescent lamps of Iranian current brands.

\section{Material and Methods}

This experimental study was conducted on 16 CFLs that were manufactured by four manufacturers including branded names and retailer owned brands. The CFLs were marked as 11, 18, 40 and 60 Watt and all of the lamps contained integral electronic ballasts. All the CFLs are used for one hundred hours (12) in the laboratory conditions using a stabilized 220 V DC power supply. The UV irradiance of various types of CFLs is measured on a three-meter long optical bench, and measurement was done in 10 , 25, 50, 100, 150 and $200 \mathrm{~cm}$ using a calibrated UV-meter. Measurement of UV irradiance was performed in three angles including $0^{\circ}, 45^{\circ}$ and $90^{\circ}$ (Figure 1). In the angle $0^{\circ}$, the lamps were orientated horizontally so that the tip of the lamp faces the input diffuser of the spectroradiometer. This was used to measure the radiation as expectedin case of standing directly under a lamp suspended from the ceiling. In the angles $45^{\circ}$ and $90^{\circ}$, UV lamps are used at desk or task lamps.

A type-666230 photometer-radiometer equipped with UVA, UVB and UVC detectors were used to measure UV irradiance in all the three ranges. Measurements were performed in a dark room maintaining the temperature at $(26 \pm 2)^{\circ} \mathrm{C}$ and the relative humidity (45\%). Following a 10 min warm-up period, the emission spectrum of each lamp was measured. Measurement were repeated for each type of CFLs and finally averaged out. Finally, the information was analyzed using SPSS-20. In order to com- pare UVA and UVB irradiance and the value of irradiance in angles of four brands, we used of one way ANOVA. A $P$ value less than 0.05 were considered to be statistically significant.

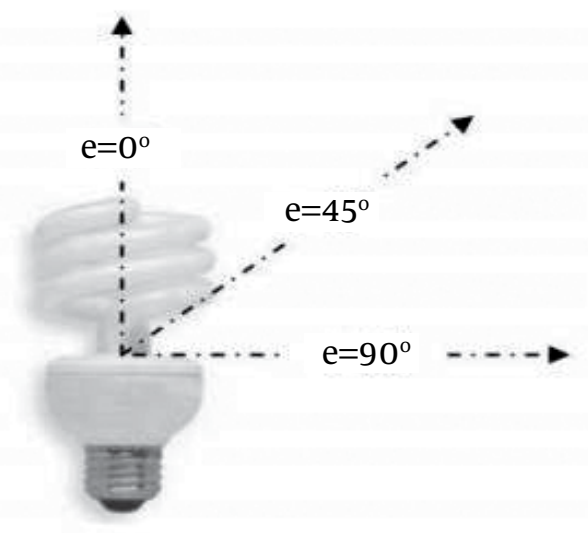

Figure 1. Angle of Measuring UV Irradiance

\section{Result}

Ultra violet irradiance was measured at the distance of 10 , $25,50,100,150$ and $200 \mathrm{~cm}$, for sixteen types of CFLs in four different Watt. At distance of more than $50 \mathrm{~cm}$, UVB irradiance could not be detected in all the cases (Table 1), on the other hand, UVC at $10 \mathrm{~cm}$ was considered to be the closest distance that people would be exposed to the lamps, even in desk top applications, irradiance could not be detected in all cases. One way ANOVA indicated that differences between UVB irradiance in three angles, and UVB irradiance in the same wattage of four brands of lamps was not significant statistically ( $\mathrm{P}>0.05)$. Table 2 showes the UVA irradiance $\left(\mathrm{W} . \mathrm{m}^{-2}\right)$ values in 10, 25, 50,100,150 and $200 \mathrm{~cm}$ and three angles for four brand CFLs in Iranian brands. As is obvious, UVA irradiance increases with increase in lamp electrical wattage. Unlike Table 2 , that UVA irradiance increases with increase in lamp electrical wattage, and emissions decreased rapidly, for UVB irradiance (Table 1), such cases were not detected, and may not detect the limit of device that was used for measurement of UV irradiance, the lowest value of UVB irradiance recorded in Pars Khazar lamp, while the highest value was recorded in Etehad lamps. One way ANOVA indicated that differences between UVA irradiance in three angles, was not significant statistically ( $\mathrm{P}>$ 0.05). The lowest UVA irradiance recorded in $45^{\circ}$, while the highest was recorded in $90^{\circ}$. In order to compare UVA irradiance in the same wattage of four brands of lamps, one way ANOVA showed that comparison between different brands was not significant $(\mathrm{P}>0.05)$. Pars khazar with the highest UVA irradiance placed in the first group and other groups were Nama Noor, Parmis and Etehad, respectively. 

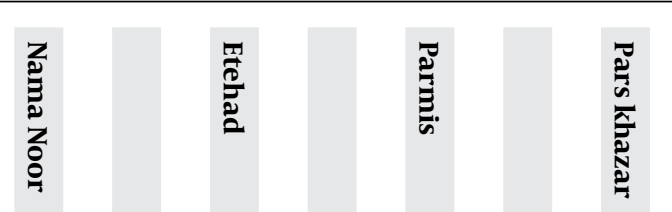

|

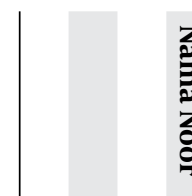

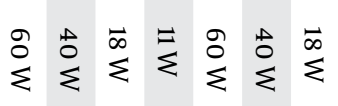

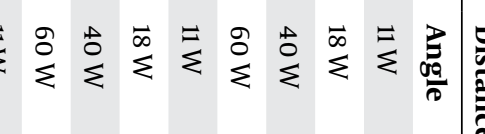

总

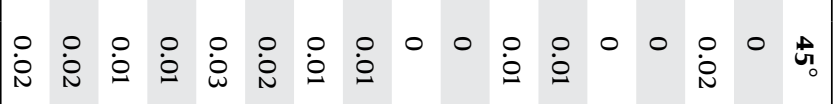

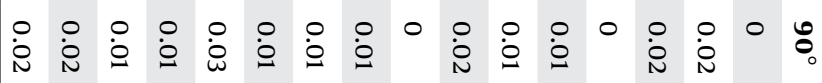

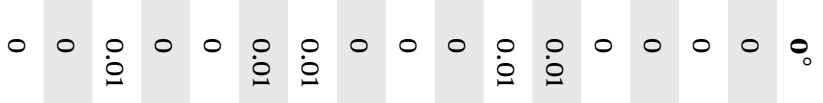

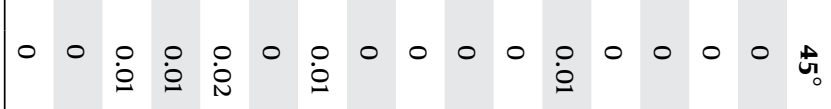

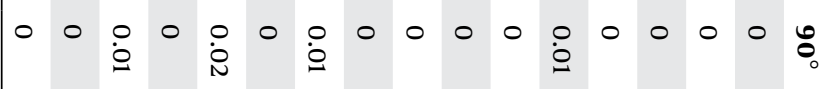

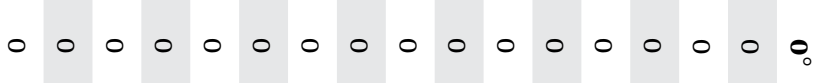

$\begin{array}{llllllllllllllll}0 & 0 & 0 & 0 & 0 & 0 & 0 & 0 & 0 & 0 & 0 & 0 & 0 & 0 & H_{0}\end{array}$

$\begin{array}{lllllllllllllllll}0 & 0 & 0 & 0 & 0 & 0 & 0 & 0 & 0 & 0 & 0 & 0 & 0 & 0 & 0 & 0 & 0 \\ 0\end{array}$ 

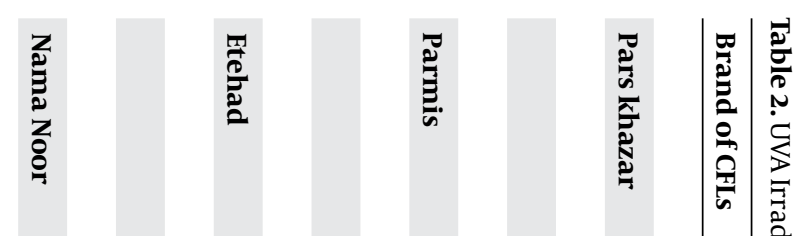

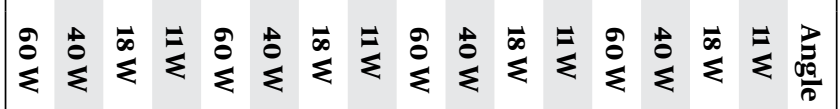

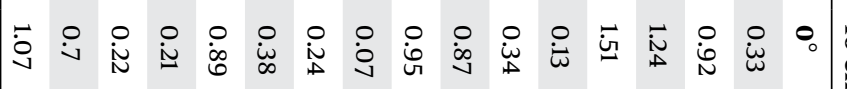

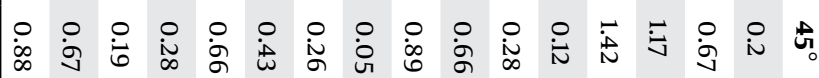

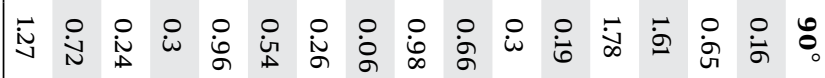

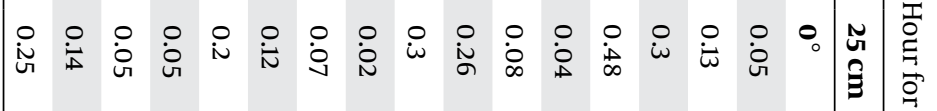

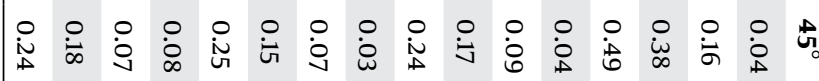

谂

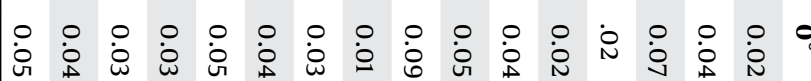

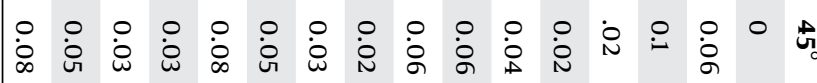

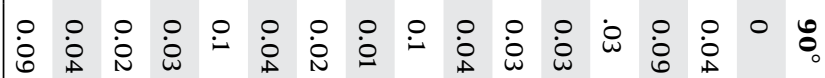

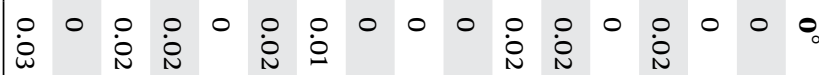

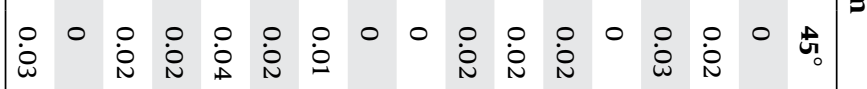

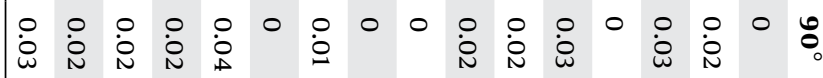

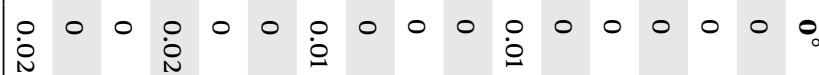

$\begin{array}{lllllllllllllllll}\dot{i} & 0 & 0 & \dot{j} & 0 & 0 & 0 & 0 & 0 & 0 & 0 & 0 & 0 & 0 & 0 & 0 & H_{1}\end{array}$

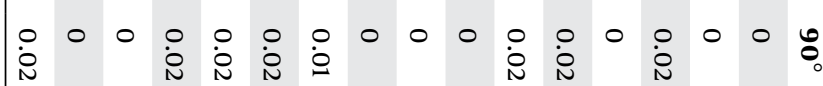

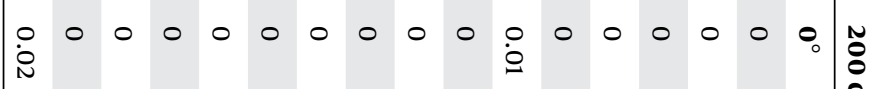

完

$\begin{array}{llllllllllllllllll} & \dot{\sim} & 0 & 0 & 0 & 0 & 0 & 0 & 0 & 0 & 0 & 0 & 0 & 0 & 0 & 0 & 0 & \vdots\end{array}$ 


\section{Discussion}

Measurements of the emissions from the lights were made in the UV part of the spectrum (100 nm to $400 \mathrm{~nm}$ ) at distances of 10, 25, 50,100, 150 and $200 \mathrm{~cm}$. Measurable values of the UVC irradiance $(100 \mathrm{~nm}-280 \mathrm{~nm})$ were not observed using UVC detectors at the distance of $10 \mathrm{~cm}$ in all of lamps. The International Commission on Non-Ionizing Radiation Protection (ICNIRP) declares which part of UVC spectrum with wave lengths below $180 \mathrm{~nm}$ (vacuum UV) are readily absorbed in air (17). That was consistent with study by Klein et al. in which the results revealed using more sensitive spectroradiometer and UV irradiance was discernible at $300 \mathrm{~nm}$, and in less values, wave length of the UV irradiance was not detected, while all of bulbs emit UV in the UVA and UVB range (16) and was inconsistence with the study by Khazova et al. in 2008 on 73 CFLs (20 single envelopes and 53 double envelope CFLs) at $2 \mathrm{~cm}$ and $20 \mathrm{~cm}$, in which the results of measurement showed that double envelope CFLs had very low UVB irradiance while single envelope lamps emitted UVB and UVC and they concluded that the UVC irradiance were probably due to defects in the phosphor coating of the glass envelope (18). According to OEL, occupational UVB exposure should be

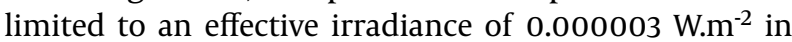
an 8 hours period (19). At $10 \mathrm{~cm}$ distance, measurement of UVB irradiance from most of CFLs was more than OEL. The highest value was recorded in Etehad lamp with 0.03 W.m2 that was 10000 times more than OEL. In a study by Eadie et al. (15) that was conductedon 5 CFLs wattage from 11,15 and 20 Watt and at 5 and $20 \mathrm{~cm}$ distance, results showed one of 11 Watt and 15 and 20 Watt CFLs emitted UVB more than the artificial optical radiation directive (20). The highest UVA irradiance was recorded in $90^{\circ}$, for UVA radiation, occupational exposure limited should be limited to $1.04166 \mathrm{~W} . \mathrm{m}^{-2}$, of all of the bulbs tested, the Etehad appear to be the safest. They emitted the lowest levels of UVA and the highest levels of UVB, among sixteen CFLs which were measured at a distance of $10 \mathrm{~cm}$. The UVA output for Pars Khazar 40 and $60 \mathrm{~W}$ was $1.61 \mathrm{~W} . \mathrm{m}^{-2}$ and $1.78 \mathrm{~W} \cdot \mathrm{m}^{-2}$, respectively, and for Nama Noor, $60 \mathrm{~W}$ was $1.07 \mathrm{~W} . \mathrm{m}^{-2}$, this shows that three CFLs would exceed the UVA exposure limit in 8 hours at a distance of $10 \mathrm{~cm}$.

Ultra violet emission was measured of various types, size and electrical powers of CFLs. Measurements were performed in controlled environmental conditions and under good regulation of electrical parameters. Measurement of three field of UV (UVA, UVB and UVC) showed that UVC emission was not observed at the distance of $10 \mathrm{~cm}$ in all of lamps. UVB irradiance in most of lamps in 10 and $25 \mathrm{~cm}$ was more than OEL, but in $50 \mathrm{~cm}$ was less than OEL. UVA irradiance in all of CFLs lamps in $25 \mathrm{~cm}$ was less than OEL. Therefore, based on the results of this study, authors recommended that CFLs lamps, due to UV radiation, especially in UVB span, be used at distances greater than $25 \mathrm{~cm}$.

\section{Acknowledgements}

The author would like to thanks the experts of physical agent laboratory for co-operative in UV measuring.

\section{Authors' Contribution}

All authors contributed to this work. Habibollah Dehghan and Hossein Ali Yousef contributed to design of setup and preparing the manuscript. Shahram Safari and Meghdad Kazemi were measured UV radiation and Behzad Mahaki performed the statistical analyses.

\section{Financial Disclosure}

The authors have indicated they have no financial relationships relevant to this article to disclose.

\section{Funding Support}

This study was financially supported by Vice President for research in Isfahan University of Medical Sciences (Project Number: 291021).

\section{References}

1. Uyaisom C. Effect of Jumbo Compact Fluorescent Lamp on the Electrical Energy Saving and Harmonics Noise. Procedia Eng. 2011;8:149-53.

2. Kumar A, Jain SK, Bansal NK. Disseminating energy-efficient technologies: a case study of compact fluorescent lamps (CFLs) in India. Energy Policy. 2003;31(3):259-72.

3. Duff JT. An Examination Into the Use of Compact Fluorescent Lamps in the Domestic Environment.J Sustain Eng Des. 2012;1(1):7.

4. Javorniczky J, Gies P, Lock L, editors. The introduction of Compact Fluorescent Lights (CFLs) and the Impact of UVR Emissions on Photosensitive People. Astralia Radiat Protec Nuclear Safe Agency; Yallabie, Victoria.

5. Mills BF, Schleich J. Why don't households see the light?: Explaining the diffusion of compact fluorescent lamps. Resour Energy Economic. 2010;32(3):363-78.

6. Parsons D. The Environmental Impact of Compact Fluorescent Lamps and Incandescent Lamps for Australian Conditions. Environ Eng. 2006;7(2):8-14

7. Cole C, Forbes PD, Davies RE, Urbach F. Effect of indoor lighting on normal skin. Ann NYAcad Sci. 1985;453:305-16.

8. Nuzum-Keim AD, Sontheimer RD. Ultraviolet light output of compact fluorescent lamps: comparison to conventional incandescent and halogen residential lighting sources. Lupus. 2009;18(6):556-60.

9. Sayre RM, Dowdy JC, Poh-Fitzpatrick M. Dermatological risk of indoor ultraviolet exposure from contemporary lighting sources. Photochem Photobiol. 2004;80:47-51.

10. Whillock MJ, McKinlay AF, Kemmler J, Forsgren PG. Ultraviolet Radiation Emissions from Miniature (Compact) Fluorescent Lamps. Light Res Tech. 1990;22(2):125-28.

11. Diffey BL. Sources and measurement of ultraviolet radiation. Method. 2002;28(1):4-13.

12. Fenton L, Ferguson J, Moseley H. Analysis of energy saving lamps for use by photosensitive individuals. Photochem Photobiol Sci. 2012;11(8):1346-55.

13. Mironava T, Hadjiargyrou M, Simon M, Rafailovich MH. The effects of UV emission from compact fluorescent light exposure on human dermal fibroblasts and keratinocytes in vitro. Photochem Photobiol. 2012;88(6):1497-506.

14. Scientific Committee on Emerging and Newly Identified Health Risks (2008). Sensitivity. Available from: http://ec.europa.eu/health/ 


\section{Safari Sh et al}

ph_risk/committees/04_scenihr/docs/scenihr_o_019.pdf Light.

15. Eadie E, Ferguson J, Moseley H. A preliminary investigation into the effect of exposure of photosensitive individuals to light from compact fluorescent lamps. Br J Dermatol. 2009;160(3):659-64.

16. Klein RS, Werth VP, Dowdy JC, Sayre RM. Analysis of compact fluorescent lights for use by patients with photosensitive conditions. Photochem Photobiol. 2009;85(4):1004-10.

17. Guidelines on limits of exposure to ultraviolet radiation of wavelengths between $180 \mathrm{~nm}$ and $400 \mathrm{~nm}$ (incoherent optical radia- tion). Health Phys. 2004;87(2):171-86.

18. Khazova M, O'Hagan JB. Optical radiation emissions from compact fluorescent lamps. Radiat Prot Dosimetry. 2008;131(4):521-5.

19. Occupational Exposure Limits. Requirements, Guidelines and Technical Guidance and Environmental Health Center. Institute for Environmental Research. 2011.

20. Chadyšiene R, Girgždys A. Assessment of Ultraviolet (UV) Radiation from Technical Sources. J Environ Eng Landscape Management. 2009;17(3):164-70. 